\title{
Front Matter: Volume 6346
}

, "Front Matter: Volume 6346," Proc. SPIE 6346, XVI International Symposium on Gas Flow, Chemical Lasers, and High-Power Lasers, 634601 (8 May 2007); doi: 10.1117/12.741632

SPIE Event: XVI International Symposium on Gas Flow, Chemical Lasers, and High-Power Lasers, 2006, Gmunden, Austria 


\section{PROCEEDINGS OF SPIE}

\section{International Symposium on \\ Gas Flow, Chemical Lasers, \\ and High-Power Lasers}

Dieter Schuöcker
Chair/Editor

4-8 September 2006

Gmunden, Austria

Organized by

Vienna University of Technology (Austria)

Argelas-Austrian Laser Association (Austria)

Sponsored by

Bundesministerium für Verkehr, Innovation und Technologie (Austria)

Amt der Oö. Landesregierung, Linz (Austria)

Schoellerbank-Die Privatbank in Iher Nähe (Austria)

EOARD-European Office of Aerospace Research and Development, Air Force Office

of Scientific Research, United States Air Force Research Laboratory (United Kingdom)

Blue Danube Airport Linz (Austria)

Österreichische Gesellschaft für Technologiepolitik (Austria)

Region Traunsee (Austria)

Fronius International GmbH (Austria)

Rofin-Sinar Laser GmbH (Germany)

Trotec Produktions-u. Vertriebs $\mathrm{GmbH}$ (Austria)

Trumpf Maschinen Austria GmbH \& Co. KG (Austria)

Erste Bank (Austria)

Swarovski Optik (Austria)

European Optical Society (Austria)

Published by

SPIE-The International Society for Optical Engineering

Volume 6346

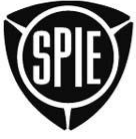

The International Society for Optical Engineering

Proceedings of SPIE-The International Society for Optical Engineering, 9780819464309, v. 6346

SPIE is an international technical society dedicated to advancing engineering and scientific applications of optical, photonic, imaging, electronic, and optoelectronic technologies. 
The papers included in this volume were part of the technical conference cited on the cover and title page. Papers were selected and subject to review by the editors and conference program committee. Some conference presentations may not be available for publication. The papers published in these proceedings reflect the work and thoughts of the authors and are published herein as submitted. The publisher is not responsible for the validity of the information or for any outcomes resulting from reliance thereon.

Please use the following format to cite material from this book:

Author(s), "Title of Paper," in XVI International Symposium on Gas Flow, Chemical Lasers, and HighPower Lasers, edited by Dieter Schuöcker, Proceedings of SPIE Vol. 6346 (SPIE, Bellingham, WA, 2007) Article CID Number.

ISSN 0277-786X

ISBN 9780819464309

Published by

SPIE-The International Society for Optical Engineering

P.O. Box 10, Bellingham, Washington 98227-0010 USA

Telephone 1 360/676-3290 (Pacific Time) · Fax 1 360/647-1445

http://www.spie.org

Copyright (c) 2007, The Society of Photo-Optical Instrumentation Engineers

Copying of material in this book for internal or personal use, or for the internal or personal use of specific clients, beyond the fair use provisions granted by the U.S. Copyright Law is authorized by SPIE subject to payment of copying fees. The Transactional Reporting Service base fee for this volume is $\$ 18.00$ per article (or portion thereof), which should be paid directly to the Copyright Clearance Center (CCC), 222 Rosewood Drive, Danvers, MA 01923. Payment may also be made electronically through CCC Online at http://www.copyright.com. Other copying for republication, resale, advertising or promotion, or any form of systematic or multiple reproduction of any material in this book is prohibited except with permission in writing from the publisher. The CCC fee code is 0277$786 \times / 07 / \$ 18.00$.

Printed in the United States of America. 


\section{Contents}

\section{Part One}

$\begin{aligned} \text { xvii } & \text { Conference Committees } \\ \text { xxi } & \text { Welcome Address } \\ x x v & \text { Introduction }\end{aligned}$

\section{GAS LASERS INCLUDING METAL VAPOUR LASERS}

634602 The future of high power laser techniques (Keynote Paper) [6346-01]

R. Poprawe, Fraunhofer Institute for Laser Technology (Germany), RWTH Aachen

(Germany), and German Scientific Laser Association WLT (Germany); P. Loosen, Fraunhofer Institute for Laser Technology (Germany) and RWTH Aachen (Germany); H.-D. Hoffmann, Fraunhofer Institute for Laser Technology (Germany)

634603 Pulsed gas lasers excited by an inductive discharge (Invited Paper) [6346-02]

A. M. Razhev, D. S. Churkin, A. A. Zhupikov, Institute of Laser Physics (Russia)

634604 Development of a short pulse and high average power $\mathrm{CO}_{2}$ laser for EUV lithography (Invited Paper) [6346-03]

T. Ariga, Extreme Ultraviolet Lithography System Development Association (Japan)

634605 Compact sealed-off cryogenic slab RF discharge CO laser [6346-04]

A. A. Ionin, L. V. Seleznev, A. V. Shelestovich, D. V. Sinitsyn, Lebedev Physical Institute (Russia)

634606 Influence of acoustic waves on TEA $\mathrm{CO}_{2}$ laser performance [6346-05]

H. von Bergmann, Univ. of Stellenbosch (South Africa); A. Forbes, T. Roberts, L. Botha, CSIR

National Laser Ctr. (South Africa)

634607 High-efficiency diode-pumped rubidium laser: experimental results [6346-06]

T. A. Perschbacher, D. A. Hostutler, T. M. Shay, Air Force Research Lab. (USA)

Pagination: Proceedings of SPIE follow an e-First publication model, with papers published first online and then in print and on CD-ROM. Papers are published as they are submitted and meet publication criteria. A unique, consistent, permanent citation identifier (CID) number is assigned to each article at the time of the first publication. Utilization of CIDs allows articles to be fully citable as soon they are published online, and connects the same identifier to all online, print, and electronic versions of the publication. SPIE uses a six-digit CID article numbering system in which:

- The first four digits correspond to the SPIE volume number.

- The last two digits indicate publication order within the volume using a Base 36 numbering system employing both numerals and letters. These two-number sets start with 00, 01, 02, 03, 04, 05, 06, 07, 08, 09, 0A, 0B ... 0Z, followed by 10-1Z, 20-2Z, etc.

The CID number appears on each page of the manuscript. The complete citation is used on the first page, and an abbreviated version on subsequent pages. 
634608 Pressure scaling of an electro-discharge singlet oxygen generator (ED SOG) [6346-07] T. V. Rakhimova, A. S. Kovalev, D. V. Lopaev, O. V. Proshina, Yu. A. Mankelevich,

A. N. Vasilieva, O. V. Braginsky, K. S. Klopovsky, N. A. Popov, A. T. Rakhimov, Moscow State Univ. (Russia); Yu. V. Kolobyanin, Russian Federal Nuclear Ctr. (Russia)

\section{CHEMICAL LASERS: COIL}

634609 Overview on the chemical oxygen-iodine laser technology (Invited Paper) [6346-08]

J. Kodymová, Institute of Physics (Czech Republic)

63460A Studies of iodine dissociation in the chemical oxygen-iodine laser (Invited Paper) [6346-09] V. Rybalkin, A. Katz, K. Waichman, D. Vingurt, Z. Dahan, B. D. Barmashenko, S. Rosenwaks, Ben-Gurion Univ. of the Negev (Israel)

63460B Performance of high pressure COIL with centrifugal bubble singlet oxygen generator [6346-10]

M. V. Zagidullin, V. D. Nikolaev, N. A. Khvatov, M. I. Svistun, Lebedev Physical Institute (Russia)

63460C Advanced spray generator of singlet oxygen [6346-11]

O. Špalek, J. Hrubý, V. Jirásek, M. Čenský, J. Kodymová, I. Picková, Institute of Physics (Czech Republic)

63460D Efficient chemical oxygen-iodine laser powered by a uniform droplet singlet oxygen generator [6346-12]

W. Chen, Y. Jin, F. Sang, Dalian Institute of Chemical Physics (China); G. Li, Dalian Univ. of Technology (China)

63460E Measuring the yield of singlet oxygen in a chemical oxygen iodine laser [6346-13] K. B. Hewett, J. E. McCord, Air Force Research Lab. (USA); M. Gupta, T. Owano, Los Gatos Research (USA)

63460F High beam quality COIL with hybrid resonators [6346-14]

J. Handke, T. Hall, F. Duschek, K. Grünewald, German Aerospace Ctr. (Germany)

$63460 \mathrm{G}$ Ejector COIL with supersonic nozzle bank based on trip-jet mixing system [6346-15] K. Tei, Tokai Univ. (Japan); K. Hirioka, M. Shiho, Tokyo Institute of Technology (Japan); K. Jyosui, M. Miyagawa, T. Fujioka, Tokai Univ. (Japan)

\section{CHEMICAL LASERS: E-OIL, AGIL, FOIL}

63460H Development of the electric discharge oxygen-iodine laser (Invited Paper) [6346-16] D. L. Carroll, J. T. Verdeyen, D. M. King, A. D. Palla, J. K. Laystrom, G. F. Benavides, CU Aerospace (USA); J. W. Zimmerman, B. S. Woodard, W. C. Solomon, Univ. of Illinois at Urbana-Champaign (USA)

634601 Chemical kinetics of discharge-driven oxygen-iodine lasers (Invited Paper) [6346-17] V. N. Azyazov, Md. H. Kabir, I. O. Antonov, M. C. Heaven, Emory Univ. (USA) 
63460J Oxygen-iodine active medium with external production of iodine in a DC glow discharge [6346-18]

P. A. Mikheyev, V. N. Azyazov, A. V. Mezhenin, N. I. Ufimtsev, A. A. Shepelenko,

A. I. Voronov, N. V. Kupryaev, S. Yu. Pichugin, M. V. Vorobyov, P.N. Lebedev Physical Institute (Russia)

63460K Kinetic studies of the autodecomposition of $\mathrm{NCl}_{3}$ [6346-19]

W. E. McDermott, Univ. of Denver Research Institute (USA); B. Nizamov, T. Henshaw,

Z. Lambert, Directed Energy Solutions (USA)

63460L The fullerene-oxygen-iodine laser: problem of scaling of the singlet oxygen generator with optically pumped fullerene [6346-20]

O. B. Danilov, I. V. Bagrov, I. M. Belousova, A. S. Grenishin, V. M. Kiselev, T. D. Murav'eva,

E. N. Sosnov, Institute for Laser Physics (Russia)

\section{EXCIMER LASERS AND OTHER UV SOURCES}

63460M Excimer-laser-driven EUV plasma source for one-shot one-pattern projection microlithography [6346-21]

P. Di Lazzaro, ENEA Frascati Research Ctr. (Italy); G. Altieri, D. Amodio, ENEA (Italy);

S. Bollanti, ENEA Frascati Research Ctr. (Italy); A. Conti, ENEA (Italy); F. Flora, ENEA Frascati Research Ctr. (Italy); T. Letardi, ENEA (Italy); L. Mezi, D. Murra, ENEA Frascati Research Ctr. (Italy); E. Tefouet Kana, El. En. SpA (Italy); A. Torre, ENEA Frascati Research Ctr. (Italy);

C. E. Zheng, El. En. SpA (Italy)

63460N Gain and fluorescence in a long-pulse $\mathrm{KrCl}$ laser [6346-22]

L. C. Casper, H. M. J. Bastiaens, P. J. M. Peters, K.-J. Boller, Univ. of Twente (Netherlands);

R. M. Hofstra, Nederlands Ctr. voor Laser Research B.V. (Netherlands)

634600 Spontaneous emission at $193 \mathrm{~nm}$ and gain measurements in $F_{2}$ containing excimer gas mixtures [6346-23]

A. V. Azarov, P. J. M. Peters, K.-J. Boller, Univ. of Twente (Netherlands)

63460P Long-term tests of compact excimer lasers [6346-24]

A. Görtler, A. Matern, C. Strowitzki, Coherent GmbH (Germany)

63460Q Influence of electrode materials and surface roughness on the homogeneity of discharges in fluorine-based excimer laser gas mixtures [6346-25]

D. Mathew, H. M. J. Bastiaens, K.-J. Boller, P. J. M. Peters, Univ. of Twente (Netherlands)

63460R Vacuum ultraviolet argon excimer laser initiated by optical-field-induced ionization electrons [6346-26]

S. Kubodera, Y. Taniguchi, Univ. of Miyazaki (Japan); T. Higashiguchi, Utsunomiya Univ. (Japan); M. Katto, Univ. of Miyazaki (Japan)

634605 Low-debris efficient laser-produced plasma extreme ultraviolet source by use of a regenerative liquid microtarget containing tin nanoparticles [6346-27]

T. Higashiguchi, N. Dojyo, Y. Senba, S. Suetake, M. Katto, S. Kubodera, Univ. of Miyazaki (Japan) 
63460T New developments in the field of diode lasers (Invited Paper) [6346-28]

F. Bammer, Vienna Univ. of Technology (Austria)

$63460 \mathrm{U}$ Laser beam application with high power fiber lasers (Invited Paper) [6346-29]

E. Beyer, Fraunhofer Institute for Material and Beam Technology (Germany) and Dresden Univ. of Technology (Germany); B. Brenner, L. Morgenthal, Fraunhofer Institute for Material and Beam Technology (Germany)

\section{SOLID STATE LASERS INCLUDING FIBRE AND DISK LASERS}

63460V Ceramic Yb: YAG microchip laser [6346-30]

E. P. Ostby, R. A. Ackerman, J. C. Huie, R. L. Gentilman, Raytheon Co. (USA)

63460W Beam characterization of a scalable $220 \mathrm{~W}$-ceramic Nd:YAG laser [6346-31]

E. Favilla, E. Sani, M. Ciofini, A. Lapucci, INOA-CNR National Institute of Applied Optics (Italy)

63460X High-power radially polarized good-quality beams from aberration compensated rodbased Nd:YAG lasers [6346-32]

I. Moshe, S. Jackel, A. Meir, Y. Lumer, E. Leibush, Soreq Nuclear Research Ctr. (Israel)

63460Y Efficient laser systems for $\mathbf{9 3 5}$ and $\mathbf{9 4 2} \mathbf{~ n m}$ for water vapour lidar [6346-33]

H. J. Eichler, F. Kallmeyer, H. Rhee, T. Riesbeck, S. Strohmaier, Technical Univ. of Berlin

(Germany)

\section{SHORT PULSE HIGH-POWER AND ULTRAHIGH-POWER LASER SYSTEMS}

$63460 Z$ Bringing picosecond $\mathrm{CO}_{2}$ lasers to the forefront of strong-field applications (Invited Paper) [6346-34]

I. Pogorelsky, V. Yakimenko, I. Pavlishin, Brookhaven National Lab. (USA); P. Shkolnikov, Stony Brook Univ. (USA); A. Pukhov, Institute of Theoretical Physics I (Germany); T. Kumita, Tokyo Metropolitan Univ. (Japan); M. Azarov, Russian Scientific Ctr. of Applied Chemistry (Russia)

634610 The development of TW and PW optical sources of femtosecond pulses on the base of hybrid laser systems with wide-aperture gas laser amplifiers [6346-35]

A. A. Ionin, A. V. Konyashchenko, Lebedev Physical Institute (Russia); B. M. Koval'chuk, Institute of High-Current Electronics (Russia); O. N. Krokhin, Lebedev Physical Institute (Russia); V. F. Losev, Institute of High-Current Electronics (Russia); G. A. Mesyats, L. D. Mikheev, A. G. Molchanov, Yu. N. Novoselov, A. N. Starodub, Lebedev Physical Institute (Russia); V. F. Tarasenko, Institute of High-Current Electronics (Russia);

S. I. Yakovlenko, General Physics Institute (Russia); V. D. Zvorykin, Lebedev Physical Institute (Russia)

634611 Q-switching with photo-elastic modulators [6346-36]

F. Bammer, Vienna Univ. of Technology (Austria) 
634612 Modification of solidification conditions through the application of pulsed Nd:YAG lasers [6346-37]

J. P. Bergmann, Technical Univ. Ilmenau (Germany); R. Holtz, LASAG AG (Switzerland);

J. Wilden, Technical Univ. IImenau (Germany)

634613 Amplification of femtosecond optical pulses in a photolytically driven XeF(C-A) laser amplifier [6346-38]

V. Tcheremiskine, Lab. Lasers, Plasmas et Procédés Photoniques, CNRS, Univ. Aix-Marseille II (France) and P.N. Lebedev Physical Institute (Russia); O. Uteza, Lab. Lasers, Plasmas et Procédés Photoniques, CNRS, Univ. Aix-Marseille II (France); V. Mislavskii, P.N. Lebedev Physical Institute (Russia); M. Sentis, Lab. Lasers, Plasmas et Procédés Photoniques, CNRS, Univ. Aix-Marseille II (France); L. Mikheev, P.N. Lebedev Physical Institute (Russia)

\section{HIGH-POWER LASER APPLICATIONS I: MATERIAL PROCESSING}

634614 LaserHybrid welding for industrial applications (Invited Paper) [6346-39]

H. Staufer, Fronius International GmbH (Austria)

634615 Laser assisted forming techniques (Invited Paper) [6346-40]

A. Kratky, Technische Univ. Wien (Austria)

634616 Closed loop control for laser beam welding (Invited Paper) [6346-41]

A. Otto, R. Hohenstein, S. Dietrich, Univ. of Erlangen-Nuremberg (Germany)

634617 Dual beam Nd:YAG laser welding: influence of lubricants to lap joint welding of steel sheets [6346-42]

M. Geiger, M. Merklein, A. Otto, A. Blankl, Univ. of Erlangen-Nuremberg (Germany)

$634618 \mathrm{CO}_{2}$ laser welding with dynamic polarization [6346-43]

S. Gräf, G. Staupendahl, T. Liebig, Friedrich-Schiller-Univ. Jena (Germany)

634619 Welding characteristics with lasers of high focusability [6346-44]

J. Weberpals, F. Dausinger, H. Hügel, Univ. Stuttgart (Germany)

$63461 \mathrm{~A}$ Establishing laser welding parameters to minimize weld-piece distortion by means of multiline laser profilometry [6346-45]

A. Gorkič, M. Jezeršek, J. Možina, J. Diaci, Univ. of Ljubljana (Slovenia)

$63461 \mathrm{~B}$ Space-saving electric-discharge $\mathrm{CO}_{2}$ laser of high (up to $14 \mathrm{~kW}$ ) radiation power with convective cooling of the working medium and gas pumping by an extended disc fan [6346-46]

Yu. V. Afonin, V. F. Filev, V. M. Fomin, A. P. Golyshev, O. B. Kovalev, A. G. Malikov, A. M. Orishich, Yu. M. Prikhod'ko, V. P. Fomichev, V. B. Shulyat'ev, Khristianovich's Institute of Theoretical and Applied Mechanics (Russia)

63461C The use of laser technology for the welding of the automotive tree mechanical clutch subject to the action of residual intrinsic magnetic field [6346-47]

G. Daurelio, Laser Material Processing Private Consulting (Italy); E. Campanile, Graziano Trasmissioni SpA (Italy); M. D'Alonzo, ELFIM s.r.l. (Italy); F. Memola Capece Minutolo, Univ. of Naples Federico II (Italy); M. Spera, Production Engineering Private Consulting (Italy);

M. Lugarà, V. Ferrandino, Univ. degli Studi di Bari (Italy) 
63461D Finite element studies of stress evolution in induction assisted laser cladding [6346-48] F. Brückner, Dresden Univ. of Technology (Germany); D. Lepski, Fraunhofer Institute for Material and Beam Technology IWS (Germany); E. Beyer, Dresden Univ. of Technology (Germany) and Fraunhofer Institute for Material and Beam Technology IWS (Germany)

$63461 \mathrm{E}$ Enhanced cladding quality through application of high frequency magnetic fields [6346-49]

J. Wilden, J. P. Bergmann, M. Dolles, Technical Univ. Ilmenau (Germany)

$63461 \mathrm{~F} \quad$ Laser cleaning of silver surfaces [6346-50]

M. Pires, J. Faustino, T. Ferraz, INETI (Portugal); K. Watkins, Univ. of Liverpool (United Kingdom)

$63461 \mathrm{G}$ Laser selectivity on cleaning museologic iron artefacts [6346-51]

G. Pereira, Univ. of Lisboa (Portugal); M. Pires, INETI (Portugal); B. Costa, Univ. of Coimbra (Portugal); F. Costa, Univ. of Lisboa (Portugal)

$63461 \mathrm{H} \quad$ Micro- and nanoprocessing of organic polymers using a laser plasma XUV source [6346-52]

H. Fiedorowicz, A. Bartnik, R. Jarocki, Military Univ. of Technology (Poland); L. Juha, Joint Research Lab./Institute of Physics and Institute of Plasma Physics (Czech Republic);

J. Kostecki, R. Rakowski, M. Szczurek, Military Univ. of Technology (Poland)

HIGH-POWER LASER APPLICATIONS II: COMBUSTION, PROPULSION, AND ENVIRONMENT

$634611 \quad$ Laser space propulsion overview (Invited Paper) [6346-53]

C. Phipps, Photonic Associates, LLC (USA); J. Luke, W. Helgeson, New Mexico Tech/Institute for Engineering Research and Applications (USA)

$63461 \mathrm{~J}$ Laser propulsion for space applications: Is it another myth or a real potential? [6346-54] J. R. Cook, The Boeing Co. (USA)

63461K Laser induced ignition (Invited Paper) [6346-55]

G. Liedl, D. Schuöcker, B. Geringer, J. Graf, D. Klawatsch, H. P. Lenz, Technische Univ. Wien (Austria); W. F. Piock, M. Jetzinger, P. Kapus, AVL List GmbH (Austria)

63461L Recent airborne laser: laser results (Invited Paper) [6346-56]

K. A. Truesdell, Airborne Laser Program Office (USA)

$63461 \mathrm{M}$ The airborne laser (Invited Paper) [6346-57]

S. Lamberson, Missile Defense Agency (USA); H. Schall, The Boeing Co. (USA); P. Shattuck, Lockheed Martin Space and Missile Corp. (USA)

63461N Impulsar: I. Experimental and theoretical investigations [6346-58]

V. V. Apollonov, V. N. Tishchenko, General Physics Institute (Russia)

634610 Impulsar: II. Experimental and theoretical investigations [6346-59]

V. V. Apollonov, V. N. Tishchenko, General Physics Institute (Russia) 
HIGH-POWER LASER/MATERIAL INTERACTION PHENOMENA, NOVEL INTERACTION PROCESSES

63461P A review of the physics and technological issues of high intensity laser shock processing of materials as a method for mechanical properties modification (Invited Paper) [6346-60]

J. L. Ocaña, M. Morales, C. Molpeceres, J. A. Porro, Univ. Politécnica de Madrid (Spain)

$63461 \mathrm{Q}$ Laser-induced plasma as a source for an intensive current to produce electromagnetic forces in the weld pool [6346-61]

G. Ambrosy, V. Avilov, P. Berger, H. Hügel, Univ. Stuttgart (Germany)

$63461 \mathrm{R}$ Bubble dynamics induced by YAG laser focusing in liquid nitrogen and cryogenic laser processing for particles [6346-62]

S. Watanabe, T. Sirato, M. Ota, K. Maeno, Chiba Univ. (Japan)

\section{NOVEL APPROACHES AND INNOVATIONS IN HIGH-POWER LASER SYSTEMS}

634615 New 1-micron laser sources: high brightness tools for industrial applications (Invited Paper) [6346-63]

M. Berger, II-VI Deutschland Development (Germany)

$63461 \mathrm{~T}$ Free electron laser status and development in the THz and $\mathrm{x}$-ray regions (Invited Paper) [6346-64]

G. P. Gallerano, A. Renieri, ENEA (Italy)

$63461 \mathrm{U}$ Intracavity beam shaping for high power thin-disk lasers (Invited Paper) [6346-66]

A. Voss, M. Abdou-Ahmed, C. Neugebauer, A. Giesen, T. Graf, Univ. Stuttgart (Germany)

$63461 \mathrm{~V}$ Gain measurements in a non-self-sustained electric discharge pumped oxygen-iodine laser cavity [6346-67]

A. Hicks, K. Fredrickson, S. Tirupathi, Y. G. Utkin, W. R. Lempert, J. W. Rich, I. V. Adamovich, The Ohio State Univ. (USA); K. L. Galbally-Kinney, W. J. Kessler, W. T. Rawlins, P. A. Mulhall, S. J. Davis, Physical Sciences Inc. (USA)

$63461 \mathrm{~W}$ Transforming the $(0,1) *$ LG mode with radial polarization to a nearly Gaussian beam by use of a spiral phase element and spatial filter [6346-68]

G. Machavariani, Y. Lumer, I. Moshe, S. Jackel, Soreq Nuclear Research Ctr. (Israel)

63461X Intracavity genetic algorithm for any distance beam parameters control [6346-69] A. Kostylev, A. Sobolev, T. Cherezova, M.V. Lomonosov Moscow State Univ. (Russia) and Adopt Ltd. (Russia); Y. Sheldakova, A. Kudryashov, Moscow State Open Univ. (Russia) and Adopt Ltd. (Russia)

$63461 Y$ Investigation of variable reflecting mirrors effects in beam quality of unstable optical resonators [6346-70]

M. H. Mahdieh, M. Shirmahi, M. Lafooti, Iran Univ. of Science and Technology (Iran) 


\section{Part Two}

NEW HIGH-POWER LASER MEDIA, LASER MODELLING, INCLUDING FLUID DYNAMICS AND FLOW INTERACTION PHENOMENA

634612 Problems of COIL fluid dynamics (Invited Paper) [6346-71]

A. Boreysho, V. Malkov, A. Savin, Laser Systems Ltd. (Russia)

634620 Time developing 3-D simulation of chemical oxygen-iodine lasers (COILs) (Invited Paper) [6346-72]

T. J. Madden, Air Force Research Lab. (USA)

634621 Modelling of subsonic COIL with an arbitrary magnetic modulation [6346-73]

J. Beránek, K. Rohlena, Institute of Physics (Czech Republic)

634622 Mixing of post-discharge $\mathrm{O}_{2} / \mathrm{He}$ flow with $\mathrm{NO}_{2} / \mathrm{He}$ flow: 3D modeling of experimental data [6346-74]

T. V. Rakhimova, Moscow State Univ. (Russia); A. P. Palov, Plasma Venture Ltd. (Russia):

Yu. A. Mankelevich, N. A. Popov, Moscow State Univ. (Russia); D. L. Carroll, CU Aerospace (USA)

634623 Numerical modeling of the multicore fiber amplifier [6346-75]

A. P. Napartovich, N. N. Elkin, V. N. Troshchieva, D. V. Vysotsky, Troitsk Institute for Innovation and Fusion Research (Russia)

DIAGNOSTICS, BEAM DELIVERY AND BEAM PROPAGATION, OPTICAL FIBRES, ATOMOSPHERIC PROPAGATION, NONLINEAR OPTICS, AND ADAPTIVE OPTICS

634624 Recent network sensing based on a combination of single mode fiber optics and semiconductor lasers (Invited Paper) [6346-76]

K. Watanabe, Soka Univ. (Japan)

634625 Aerodynamic window for high precision laser drilling [6346-77]

S. Sommer, Forschungsgesellschaft für Strahlwerkzeuge (Germany) F. Dausinger, P. Berger,

H. Hügel, Univ. Stuttgart (Germany)

634626 LIBS micro-analysis of solid aluminum samples by use of optical fibers as light guide [6346-78]

T. Stehrer, J. Heitz, Johannes-Kepler Univ. Linz (Austria)

634627 Asymmetrical thermal blooming effect of intense laser beam propagation through atmosphere [6346-79]

X. Du, Chinese Academy of Engineering (China) and Institute of Applied Physics and Computational Mathematics (China); F. Zhang, Institute of Applied Physics and Computational Mathematics (China)

634628 Turbulent phase screens generated by covariance approach and their application in numerical simulation of atmospheric propagation of laser beam [6346-80]

H.-X Yan, S. Chen, S.-S. Li, Institute of Mechanics (China) 
634629 Adaptive optics and high power pulse lasers [6346-81]

A. Kudryashov, A. Alexandrov, V. Zavalova, A. Rukosuev, V. Samarkin, Moscow State Open Univ. (Russia) and Adopt Ltd. (Russia)

63462A Bimorph flexible mirror for vortex beam formation [6346-82]

A. Sobolev, T. Cherezova, Moscow State Univ. (Russia); V. Samarkin, A. Kudryashov, Moscow State Open Univ. (Russia)

\section{POSTER SESSION}

63462B $\quad\left({ }^{12} \mathrm{CO}_{2}+{ }^{13} \mathrm{CO}_{2}+{ }^{14} \mathrm{~N}_{2} \mathrm{O}+{ }^{15} \mathrm{~N}^{14} \mathrm{NO}\right)$-active media of high pressure with optical pumping by $\mathrm{HF}$ laser radiation [6346-83]

M. A. Azarov, B. S. Alexandrov, A. V. Arsenjev, A. P. Burtsev, V. A. Drozdov, Russian Scientific Ctr. (Russia); V. V. Kalinovsky, Russian Federal Nuclear Ctr., VNIIEF (Russia);

V. I. Mashendzhinov, Russian Scientific Ctr. (Russia); G. M. Mishchenko, Russian Federal

Nuclear Ctr., VNIIEF (Russia); G. A. Troshchinenko, Russian Scientific Ctr. (Russia)

63462C 3D simulation of COIL nozzle flow [6346-84]

A. Savin, S. Druzhinin, D. Vasiliev, Laser Systems Ltd. (Russia)

63462D A computational fluid dynamics simulation of a supersonic chemical oxygen-iodine laser [6346-85]

K. Waichman, V. Rybalkin, A. Katz, Z. Dahan, B. D. Barmashenko, S. Rosenwaks, Ben-Gurion Univ. of the Negev (Israel)

63462E Active medium gain study of electric-discharge oxygen-iodine laser [6346-86] Y. Kolobyanin, Y. Adamenkov, B. Vyskubenko, L. Goryachev, S. Ilyin, A. Kalashnik, Russian Federal Nuclear Ctr., VNIIEF (Russia); T. Rakhimova, M.V. Lomonosov Moscow State Univ. (Russia); G. Rogozhnikov, Russian Federal Nuclear Ctr., VNIIEF(Russia)

63462F Aerosol scattering of supercontinuum radiation formed upon femtosecond laser pulse filamentation in the atmosphere [6346-87]

A. A. Zemlyanov, Y. E. Geints, D. V. Apeksimov, Institute of Atmospheric Optics (Russia)

63462G Analysis of transverse field distributions in Porro prism resonators [6346-88]

I. A. Litvin, CSIR National Laser Ctr. (South Africa) and B.I. Stepanov Institute of Physics

(Belarus); L. Burger, A. Forbes, CSIR National Laser Ctr. (South Africa)

$63462 \mathrm{H} \quad$ Atomic iodine production by decomposing $\mathrm{CF}_{3} \mathrm{l}$ in $\mathrm{RF}$ discharge [6346-89]

G. Li, F. Sang, L. Duo, Dalian Institute of Chemical Physics (China)

634621 Calorimetric and calorimetric-fluorimetric methods for the measurement of singlet oxygen concentrations [6346-90]

V. K. Ikonnikov, S. A. Sirotin, S. S. Kharchenko, Russian Scientific Ctr. (Russia); B. Lacour, V. Puech, Univ. de Paris-Sud (France)

63462J COIL with supersonic injection of chemically produced atomic iodine [6346-91] V. Jirásek, O. Špalek, M. Čenský, J. Kodymová, I. Picková, Institute of Physics (Czech

Republic); I. Jakubec, Institute of Inorganic Chemistry (Czech Republic) 
$63462 \mathrm{~K}$ Computer analysis of external effect on the discharge characteristics of gas mixture [6346-92]

M. Taniwaki, K. Shimizu, Institute of Research and Innovation (Japan); S. Sato, National Defense Medical College Research Institute (Japan); Y. Tsuchiya, Y. Maekawa, M. Iyoda, Chiba Institute of Technology (Japan)

63462L Control of isomerization in photochromic molecule with ultraviolet and visible laser [6346-93]

S. Akita, Y. Ishii, S. Maruta, K. Watanabe, Soka Univ. (Japan)

63462M Crack processing in a resin material using nano-pulsed second harmonic Nd:YAG laser for personal identification system [6346-94]

D. Tokita, Y. Ishii, Y. Kubota, K. Watanabe, Soka Univ. (Japan)

63462N CW chemical HF/DF laser operating in the Q-switch mode [6346-95]

M. A. Azarov, B. S. Alexandrov, Russian Scientific Ctr. (Russia); V. I. Kuprenyuk, S.I. Vavilov State Optical Institute (Russia); Yu. P. Maximov, V. I. Mashendzhinov, Russian Scientific Ctr. (Russia); A. Yu. Rodionov, S.I. Vavilov State Optical Institute (Russia); M. A. Rotinian, V. V. Sudarikov, N. E. Tret'jakov, I. A. Feodorov, A. L. Etzina, Russian Scientific Ctr. (Russia)

634620 Damage threshold of acrylic polymer jackets surrounded with optical fiber by UV laser [6346-96]

Y. Maezono, I. Yousuke, K. Kurosawa, JST Satellite Miyazaki, Science and Technology

Agency (Japan); M. Katto, A. Yokotani, Univ. of Miyazaki (Japan)

63462P Development of supersonic oxygen-iodine laser by RF discharge [6346-97]

K. Abe, T. Uchiyama, Keio Univ. (Japan)

63462Q Efficient TEA CO 2 -laser-based coating removal system [6346-98]

F. J. Prinsloo, S. P. van Heerden, E. Ronander, Scientific Development and Integration Ltd. (South Africa); L. R. Botha, CSIR National Laser Ctr. (South Africa)

63462R Enhancement of extreme ultraviolet emission from a lithium plasma by use of dual laser pulses [6346-99]

T. Higashiguchi, K. Kawasaki, Y. Senba, S. Suetake, M. Katto, S. Kubodera, Univ. of Miyazaki (Japan)

634625 Experimental study of disharge characteristics and fluorine atom yield on DC discharge of $\mathrm{NF}_{3} / \mathrm{He}$ [6346-100]

L. Duo, S. Tang, H. YU, J. Wang, L. Li, Y. Jin, B. Yang, F. Sang, Dalian Institute of Chemical

Physics (China)

63462T Flexible laser simulator constructed in the integrated information processing environment [6346-101]

Y. Tsuchiya, Chiba Institute of Technology (Japan); M. Taniwaki, K. Shimizu, Institute of Research and Innovation (Japan); S. Sato, National Defense Medical College Research Institute (Japan); Y. Maekawa, M. Iyoda, Chiba Institute of Technology (Japan)

$63462 \mathrm{U}$ Fluorescence and transient absorption spectra of $\mathrm{Ar} / \mathrm{Kr} / \mathrm{F}_{2}$ mixtures excited by e-beam [6346-102]

V. D. Zvorykin, I. V. Kholin, A. O. Levchenko, A. G. Molchanov, N. N. Ustinovskii,

D. A. Zayarnyi, P.N. Lebedev Physical Institute (Russia) 
$63462 \mathrm{~V}$ High speed imaging of drilling process of thin silicon substrates with double-pulsed femtosecond laser [6346-103]

A. Yokotani, H. Fukumoto, Y. Kanamitsu, S. Nagatomo, Univ. of Miyazaki (Japan);

Y. Maezono, JST Satellite Miyazaki (Japan); M. Katto, Univ. of Miyazaki (Japan)

63462W Influence of gas mixture on the production of singlet delta oxygen [6346-104]

D. Xiao, X. Wang, X. Zhang, Huazhong Univ. of Science and Technology (China)

63462X Influence of laser parameters on laser ultrasonic efficiency [6346-105]

A. Forbes, L. Botha, CSIR National Laser Ctr. (South Africa); N. du Preez, Scientific Development and Integration Ltd. (South Africa); T. Drake, Lockheed Martin Aeronautics Co. (USA)

63462Y Influence of the processing parameters on the ultrashort laser ablation of metals [6346-106] P. A. Atanasov, N. N. Nedialkov, Institute of Electronics (Bulgaria)

$63462 Z$ Intracavity phase element improves laser mode stability [6346-107]

G. Machavariani, Soreq Nuclear Research Ctr. (Israel); N. Davidson, A. A. Ishaaya, A. A. Friesem, Weizmann Institute of Science (Israel)

634630 Investigation of cryosorption vacuum system and operation process for COIL [6346-108]

L. Xia, Dalian Univ. of Technology (China) and Dalian Institute of Chemical Physics (China);

J. Wang, Dalian Univ. of Technology (China); F. Sang, S. Zhao, Y. Jin, B. Fang, Dalian Institute of Chemical Physics (China)

634631 ISTC projects devoted to improving laser beam quality [6346-109]

Yu. I. Malakhov, International Science and Technology Ctr. (Russia)

634632 Laser material micro-working (LM $\mathrm{LW})$ : some new surface processes [6346-1 10]

G. Daurelio, Laser Material Processing Private Consulting (Italy); M. D'Alonzo, ELFIM s.r.l. (Italy)

634633 Laser ablation and competitive technologies in paint stripping of heavy anticorrosion coatings [6346-111]

G. D. Schuöcker, HTC Systems GmbH \& Co. KG (Austria); R. Bielak, Vienna Univ. of

Technology (Austria)

634634 Laser ion source for Ge implantation of silicon surfaces [6346-112]

F. Belloni, V. Nassisi, Univ. of Lecce (Italy); L. Torrisi, Univ. of Messina (Italy); J. Wolowski, IPPLM (Poland); D. Doria, A. Lorusso, L. Velardi, Univ. of Lecce (Italy)

634635 Laser recleaning of a Bronze Age prehistoric dolmen [6346-113]

G. Daurelio, S. E. Andriani, I. M. Catalano, CNISM, Univ. and Polytechnic of Bari (Italy) and Univ. of Bari (Italy); A. Albanese, Univ. of Bari (Italy)

634636 Marker and pen graffiti cleaning on diverse calcareous stones by different laser techniques [6346-114]

S. E. Andriani, I. M. Catalano, Univ. of Bari (Italy) and CNISM, Univ. and Polyłechnic of Bari (Italy); G. Daurelio, CNISM, Univ. and Polytechnic of Bari (Italy); A. Albanese, Univ. of Bari (Italy) 
634637 Modelling coil with iodine atoms produced by pulsed electric discharge [6346-116] A. P. Napartovich, I. V. Kochetov, Troitsk Institute for Innovation and Fusion Research (Russia); N. P. Vagin, N. N. Yuryshev, P.N. Lebedev Physical Institute (Russia)

634638 Modification studies of polyethylene by multi-ion implantation by laser ion source [6346-117]

V. Nassisi, Univ. of Lecce (Italy); L. Torrisi, A. Visco, Univ. of Messina (Italy); A. Lorusso, L. Velardi, G. Caretto, F. Belloni, Univ. of Lecce (Italy); J. Beltrano, N. Campo, Univ. of Messina (Italy)

634639 Numerical studies on a modified negative-branch confocal unstable resonator (MNBUR) [6346-118]

T. Hall, K. M. Grünewald, J. Handke, German Aerospace Ctr. (Germany)

63463A Observation on instability of excitation discharge in TEA gas leasers with supersonic flow [6346-119]

G. Imada, T. T. Son, M. Suzuki, W. Masuda, Nagaoka Univ. of Technology (Japan)

63463B Picosecond mid-infrared amplifier for high average power [6346-120]

L. R. Botha, CSIR National Laser Ctr. (South Africa); S. P. van Heerden, F. J. Prinsloo, Scientific Development and Integration Ltd. (South Africa)

63463C Pulsed injection of the feedback signal to a $\mathrm{CW}$ and pulsed RF excited $\mathrm{CO}_{2}$ slabwaveguide laser [6346-121]

D. A. Wojaczek, E. F. Plinski, Ł. Rosiński, R. Trawiński, A. B. Dobrucki, Wroclaw Univ. of Technology (Poland)

63463D Pulsed CO laser and laser amplifier operating on oxygen containing gas mixtures [6346-122]

A. A. Ionin, Y. M. Klimachev, A. A. Kotkov, A. Yu. Kozlov, L. V. Seleznev, R. P. Andrusenko, P.N. Lebedev Physical Institute (Russia)

63463E Pulsed laser deposition for polycrystalline hydroxyapatite coatings [6346-123] M. Katto, K. Ishibashi, A. Yokotani, T. Higashiguchi, S. Kubodera, K. Kurosawa, Univ. of Miyazaki (Japan); T. Nakayama, H. Katayama, Kinki Univ. (Japan); M. Fujita, Institute for Laser Technology (Japan); N. Abe, M. Tsukamoto, Osaka Univ. (Japan)

63463F Pulse-periodic chemical oxygen-iodine laser with active medium formation by volumetric electric discharge [6346-124]

S. D. Velikanov, V. G. Gorelov, I. V. Gostev, Ye. V. Ireshev, V. V. Kalinovsky, I. A. Komissarov, V. V. Konovalov, I. V. Konovalov, V. N. Mikhalkin, V. D. Nikolaev, I. V. Sevryugin,

A. V. Smirnov, R. E. Sobolev, L. N. Shornikov, Russian Federal Nuclear Ctr. (Russia)

$63463 \mathrm{G}$ Selection of spectral lines in MOPA system of the pulsed chemical photo-initiated HF laser [6346-125]

B. S. Alexandrov, A. V. Arsenjev, A. S. Averjanov, M. A. Azarov, V. A. Drozdov,

G. A. Troshchinenko, Russian Scientific Ctr. (Russia)

$63463 \mathrm{H}$ Selective laser cleaning of chlorine on ancient coins [6346-126]

D. Aiello, ENEL Produzione S.p.A. (Italy); A. Buccolieri, G. Buccolieri, Univ. of Lecce (Italy) and INFN (Italy); A. Castellano, M. Di Giulio, Univ. of Lecce (Italy); L. S. Leo, A. Lorusso, Univ. of Lecce (Italy) and INFN (Italy); G. Nassisi, Univ. of Lecce (Italy); V. Nassisi, Univ. of Lecce (Italy) and INFN (Italy); L. Torrisi, Univ. of Messina (Italy) 
634631 Singlet delta oxygen production in a slab discharge in oxygen [6346-127]

A. A. Ionin, M. P. Frolov, P.N. Lebedev Physical Institute (Russia); I. V. Kochetov, TRINITI (Russia); V. N. Ochkin, P.N. Lebedev Physical Institute (Russia); A. P. Napartovich, TRINITI (Russia); Y. P. Podmar'kov, P.N. Lebedev Physical Institute (Russia); O. A. Rulev, TRINITI (Russia); S. Y. Savinov, L. V. Seleznev, D. V. Sinitsyn, N. P. Vagin, N. N. Yuryshev, P.N. Lebedev Physical Institute (Russia)

63463J Singular wavefront reconstruction with the tilts measured by Shack-Hartmann sensor [6346-128]

V. Aksenov, Institute of Atmospheric Optics (Russia); I. Izmailov, Tomsk State Univ. (Russia); F. Kanev, Tomsk Polytechnical Univ. (Russia); F. Starikov, Russian Federal Nuclear Ctr., VNIIEF (Russia)

63463K Start features of supersonic chemical laser (SCL) channel operating with pressure recovery system (PRS) [6346-129]

A. S. Boreysho, V. M. Malkov, Laser Systems Ltd. (Russia)

63463L Study on $\mathrm{HN}_{3}$ production for all gas-phase iodine laser [6346-130]

S. K. Tang, L. P. Duo, Y. Q. Jin, H. J. YU, J. Wang, F. T. Sang, Dalian Institute of Chemical Physics (China)

$63463 \mathrm{M}$ Temperature and stress prediction for $\mathrm{CO}_{2}$ laser heating glass plate [6346-131]

X. Wang, J. Jiao, H. Lu, Huazhong Univ. of Science and Technology (China)

63463N The development of $\mathrm{XeF}(\mathrm{C}-\mathrm{A})$ lasers by optical pumping [6346-132]

J. Liu, L. Yu, L. Ma, A. Yi, C. Huang, X. An, H. Li, G. Chen, Y. Zhang, J. Su, Z. Zeng, X. Ye, Northwest Institute of Nuclear Technology (China)

634630 The diagnostics of plasmas produced by a high power excimer laser system [6346-133] X. Zhao, J. Liu, A. Yi, H. Hua, G. Zheng, Q. Xue, H. Qian, C. Huang, W. Xiao, X. Huang, X. Ye, L. Wang, Northwest Institute of Nuclear Technology (China)

63463P The repetitively pulsed electro-discharge $\mathbf{H F}$ laser on chain chemical reaction $\mathbf{F}_{2}+\mathrm{H}_{2}$ [6346-134]

M. A. Azarov, B. S. Alexandrov, A. V. Arsenjev, V. A. Drozdov, E. A. Klimuk, C. A. Kutumov, V. V. Sudarikov, G. A. Troshchinenko, Russian Scientific Ctr. (Russia); B. Lacour, Univ. ParisSud II (France)

63463Q Three-dimensional flow structures in counter-flow jet SOG [6346-135] I. M. Evdokimov, A. V. Savin, A. V. Trilis, S. L. Druzhinin, K. O. Alekseev, Laser Systems Ltd. (Russia)

63463R Three-dimensional plastic coloring by laser plastic coloring method using waveguide $\mathrm{CO}_{2}$ laser [6346-136]

M. Iwata, D. Tokita, Y. Ishii, Y. Kubota, K. Watanabe, Soka Univ. (Japan)

63463S Ultrafast phase transition of Si by femtosecond laser pulse irradiation [6346-137]

M. Fujita, Institute for Laser Technology (Japan); Y. Izawa, Osaka Univ. (Japan); M. Hashida, Kyoto Univ. (Japan); Y. Setsuhara, Y. Izawa, C. Yamanaka, Osaka Univ. (Japan)

63463T Void creating inside a transparent resin material using nano-pulse Nd:YAG laser [6346-138] S. Yamamoto, S. Takeuchi, D. Tokita, Y. Ishii, Y. Kubota, K. Watanabe, Soka Univ. (Japan) 
$63463 \mathrm{U}$ Wave front sensing of an optical vortex [6346-139]

F. A. Starikov, Russian Federal Nuclear Ctr., VNIIEF (Russia); V. P. Aksenov, I. V. Izmailov, F. Yu. Kanev, Institute of Atmospheric Optics (Russia); G. G. Kochemasov, S. M. Kulikov, A. N. Manachinsky, N. V. Maslov, A. V. Ogorodnikov, S. A. Sukharev, Russian Federal Nuclear Ctr., VNIIIEF (Russia)

Author Index 


\title{
Conference Committees
}

\author{
Honorary Chair \\ Eduard Mainoni, State Secretary (Austria) \\ Conference Chair \\ Dieter Schuöcker, Vienna University of Technology (Austria) \\ International Advisory Committee
K. M. Abramski (Poland)
R. A. Ackerman (USA)
V. V. Appollonov (Russia)
P. Atanasov (Bulgaria)
M. Autric (France)
H. J. Baker (United Kingdom)
B. D. Barmashenko (Israel)
D. D. Bhawalkar (India)
W. L. Bohn (Germany)
A. S. Boreysho (Russia)
D. L. Carroll (USA)
R. L. Cook (United Kingdom)
P. Di Lazzaro (Italy)
$X$. Du (China)
J. Eichler (Germany)
M. Farsari (Greece)
T. Fujioka (Japan)
M. Gower (United Kingdom)
T. Graf (Germany)
D. R. Hall (United Kingdom)
H. Hügel (Germany)
A. A. Ionin (Russia)
R. Jalin (France) \\ K. Kasuya (Japan) \\ J. Kodymová (Czech Republic) \\ E. M. Kudriavtsev (Russia) \\ A. Lapucci (Italy) \\ P. Loosen (Germany) \\ K. Maeno (Japan) \\ A. K. Nath (India) \\ P. J. M. Peters (Netherlands) \\ J. P. Pocholle (France) \\ J. P. Reilly (USA) \\ K. Rohlena (Czech Republic) \\ S. Rosenwaks (Israel) \\ N. V. Sabotinov (Bulgaria) \\ F. Sang (China) \\ D. Schuöcker (Austria) \\ V. F. Tarasenko (Russia) \\ F. K. Tittel (USA) \\ D. W. Trainor (USA) \\ K. A. Truesdell (USA) \\ J. Tulip (Canada) \\ R. F. Walter (USA) \\ K. Watanabe (Japan) \\ H.-X. Yan (China)
}

Local Organizing Committee

Dieter Schuöcker, Conference Chair

Gerhard Liedl, Deputy Chair

Helmut Müller

Birgit Mosser-Schuöcker

Robert Bielak

Paul Novak 
Session Chairs

Opening Session

Dieter Schuöcker, Vienna University of Technology (Austria)

Gas Lasers Including Metal Vapour Lasers

Andrey A. Ionin, P.N. Lebedev Physical Institute (Russia)

Chemical Lasers: COIL

Jarmila Kodymová, Institute of Physics (Czech Republic)

Chemical Lasers: E-OIL, AGIL, FOIL

Tomoo Fujioka, Institute for Applied Optics and Institute of Laser Technology (Japan)

Excimer Lasers and Other UV Sources

Michel Autric, Mediterranean University Aix-Marseille (France)

Diode Lasers

Ferdinand Bammer, Vienna University of Technology (Austria)

Solid State Lasers Including Fibre and Disk Lasers

Eckhard Beyer, Franhofer Institute for Material and Beam Technology

(Germany) and Dresden University of Technology (Germany)

Short Pulse High-Power and Ultrahigh-Power Laser Systems

Ferdinand Bammer, Vienna University of Technology (Austria)

High-Power Laser Applications I: Material Processing

Helmut Hügel, University of Stuttgart (Germany)

Norbert Rozsenich, Austrian Society for Technological Policy (Austria)

Margarida Pires, National Institute for Engineering, Technology and Innovation (Portugal)

Alexander Kratky, Vienna University of Technology (Austria)

High-Power Laser Applications II: Combustion, Propulsion, and Environment

José Luis Ocaña, Polytechnical University of Madrid (Spain)

Gerhard Liedl, Vienna University of Technology (Austria)

High-Power Laser/Material Interaction Phenomena, Novel Interaction Processes

Xiangwan Du, Chinese Academy of Engineering Physics (China) and Institute of Applied Physics and Computational Mathematics (China)

Novel Approaches and Innovations in High-Power Laser Systems

Manfred Berger, II-VI Deutschland Development (Germany) 
New High-Power Laser Media, Laser Modelling, Including Fluid Dynamics and Flow Interaction Phenomena

Robert Bielak, Vienna University of Technology (Austria)

Diagnostics, Beam Delivery and Beam Propagation, Optical Fibres, Atomospheric Propagation, Nonlinear Optics, and Adaptive Optics Kazuhiro Watanabe, Soka University (Japan) 
Downloaded From: https://www.spiedigitallibrary.org/conference-proceedings-of-spie on 26 Apr 2023

Terms of Use: https://www.spiedigitallibrary.org/terms-of-use 


\section{Welcome Address}

\section{Eduard Mainoni, State Secretary, Austrian Government}

Let me first welcome Prof. Schuöcker on behalf of the organizers of this conference and thank him for his opening words! Esteemed Representative of the Upper Austrian Regional Parliament! It is a great pleasure for me to welcome you here at the lovely village of Gmunden at the XVI International Symposium on Gas Flow, Chemical Lasers, and High-Power Lasers. I appreciate the honour to open your conference especially since Gmunden is quite close to the place where I was born. Anyway, I do hope that this pleasant environment will promote the creativity and fertility of your ideas and debates.

Today, most of the European and industrialised countries face an urgent need to restructure their economy and society in order to meet the challenges of the $21 \mathrm{st}$ century. Modern societies have to realise higher economic growth through improved competitiveness and productivity. They have to adapt to the changing economic realities brought about by the globalisation of markets and the tremendous pace of technological change. Our innovation performance is crucially dependent on strengthening investment in and the use of new technologies. Thus research, technology, and innovation policy addressing the complex system of our knowledge-based economies have become a top priority on the political agenda all over the world.

Looking at the attendance list of this conference, covering Americans, Asians, Europeans, and Russians, I might say that the audience here is a perfect proof of this globalised knowledge society.

Yet stressing the national and regional aspects, let me make some remarks on the Austrian landscape in general and especially on laser technology, since this is the subject of the conference. In recent years Austria has managed to catch up considerably in terms of research, technology, and innovation policy. Over the last five years, the research quota in Austria has risen from 1.9 to 2.43 percent (share of GDP) and is now significantly above the EU average. Important structural reforms such as the establishment of the Austrian Research Promotion Agency (FFG) and the reform of the Fund for the Promotion of Scientific Research (FWF) assure greater efficiency in the innovation system. Today these results show that Austria has the prospect of catching up with the top European and global performers in research, technology, and innovation. 
One of the most innovative fields of research is laser technology. This kind of technology has a long history in Austria. Even more, I might say that Austria has a proven historical track record in laser technology. Considerable contributions toward the invention of laser light have been made by Austrian researchers:

- wave mechanics and theory of waves by Schrödinger and Doppler

- invention of feedback effects by Meißner

- theory of gas flows by Mach

- theory of optical fibres by Kogelnik.

However, looking into the present there is no need to hide either:

- Austrian universities have been in the vanguard of the first industrial gas laser.

- Universities and Austrian companies play a key role in the area of optical pulses in the 10-femtosecond range.

- Several companies are in the global lead concerning hybrid welding technologies or laser based engraving.

Until now Austrian research activities carried out in the laser domain have significantly increased over the years and spread over several initiatives, programmes, and instruments. The so-called General Programme of the Austrian Research Promotion Agency has funded important industrial R\&D projects over decades. Various aspects of laser technologies are covered in competence centres and labs dealing with new materials. Under the roof of the Austrian Nano Initiative and the top-down programme FIT-IT, several contracts have been signed in laser-related areas such as optoelectronics or photonics. Moreover, I should mention the Austrian Laser Association, Argelas, who - together with the Vienna University of Technology - is the organiser of this conference. Argelas is a national platform reassembling some 60 industrial key actors. Last but not least, let's not forget the European Programmes such as IST or NMP, where Austria has exhibited an extraordinary performance in laser related domains.

Being in such a good company with excellent experts from all over the world, it's needless to stress the importance of laser technologies to industrial applications. As you all know better than me, its impact is considerable both in terms of sustainability and in terms of bandwidth.

As far as we can assess the amount of application areas for laser in Austria it counts up to approximately 2,000 different industrial actors, with a clear tendency of enlargement to various sectors:

- high-tech applications in the sector of mechanical

- electrical or process plant engineering

- automotive industries

- health technologies

- consumer electronics

- microelectronics and so on and so forth, enabled or empowered by laser technologies. 
Austrian global players such as Berndorf, Böhler-Uddeholm, Electrovac, Fronius, Magna, Palfinger, Swarovski, Trodat or Voest Alpine Stahl - to name just a few in random order - benefit in their daily business from the effects and the stimulus of highly bundled light.

Coming to an end, I may express my conviction that the future of laser technologies is represented by you and your work. In this sense I would like to thank you for your attendance and your engagement in preparing this meeting. I wish you creative and inspiring discussions, and interesting and enriching days in Gmunden. 
Downloaded From: https://www.spiedigitallibrary.org/conference-proceedings-of-spie on 26 Apr 2023

Terms of Use: https://www.spiedigitallibrary.org/terms-of-use 


\section{Introduction}

High-power lasers, as of carbon dioxide type, Nd:YAG lasers, diode lasers, excimer lasers and chemical lasers as chemical oxygen iodine lasers (COIL), show wave lengths that span from the range of the far infrared above 10um down to infrared close to the visible range and ultraviolet, whereas the wavelength is most important for the absorption and transmission of laser radiation by a certain material. The beam power reaches up to megawatts in the case of COIL lasers and the focus size can become as small as $10 \mu \mathrm{m}$ in the case of the most recent Nd:YAG lasers, whereas the last two properties of the beam power and the focus size are of crucial importance for the applications in material processing, since the focus size determines the sharpness of the beam tool and the beam power the force acting on the tool. Applications of these lasers besides material processing as already mentioned can be found in energy transmission, combustion and propulsion.

All these topics were covered during the XVI International Symposium on Gas Flow, Chemical Lasers, and High-Power Lasers which took place in Austria in September 2006. Nearly 200 presentations were given by many world recognized scientists but also by young and upcoming colleagues. Most papers show high quality. Collectively they cover a variety of topics, being well distributed over the field of the conference as defined above.

There were numerous highlights among these papers, for instance lectures that discussed the competition between the two most recent types of industrial lasers, namely, disc lasers and fibre lasers, whereas beam parameter products have been achieved that are considerably smaller than for conventional high-power lasers and allow new applications such as remote welding or the generation of three-dimensional structures with very high quality by melting down and welding powderised materials.

Further highlights in the field of material processing applications were new hybrid processes where conventional technologies are advantageously combined with the impact of high-power lasers as for instance in welding or metal forming.

Besides material processing further fascinating topics treated at the conference were propulsion with lasers, the ignition of combustion processes as in motors and also applications of a new one-megawatt COIL device for energy transmission in defence.

Summarising, the actual conference demonstrates nice progress in the field of high-power lasers and their applications and contributes to the worldwide diffusion of new results to the scientific community.

Dieter Schuöcker 
Downloaded From: https://www.spiedigitallibrary.org/conference-proceedings-of-spie on 26 Apr 2023

Terms of Use: https://www.spiedigitallibrary.org/terms-of-use 